\title{
Selective ablation of photovoltaic materials with UV laser sources for monolithic interconnection of devices based on a-Si:H
}

C. Molpeceres ${ }^{\mathrm{a}, *}$, S. Lauzurica ${ }^{\mathrm{a}}$, J.J. García-Ballesteros ${ }^{\mathrm{a}}$, M. Morales ${ }^{\mathrm{a}}$, G. Guadaño ${ }^{\mathrm{a}}$, J.L. Ocaña ${ }^{\mathrm{a}}$, S. Fernández ${ }^{\mathrm{b}}$, J.J. Gandía ${ }^{\mathrm{b}}$, F. Villar ${ }^{\mathrm{c}}$, O. Nos ${ }^{\mathrm{c}}, \mathrm{J}$ Bertomeu ${ }^{\mathrm{c}}$

a Centro Láser UPM, Univ. Politécnica de Madrid, Crta. de Valencia Km 7.3, 28031 Madrid, Spain

b Dept. de Energías Renovables, Energía Solar Fotovoltaica, CIEMAT, Avda, Complutense 22, 28040 Madrid, Spain

c CeRMAE Dept. Física Aplicada i Òptica, Universitat de Barcelona, Av. Diagonal 647, 08028

Barcelona, Spain

* Corresponding author. Tel.: +34 913363098; fax: +34 913363000.

E-mail address: carlos.molpeceres@upm.es

\section{ABSTRACT}

Lasers are essential tools for cell isolation and monolithic interconnection in thin-film-silicon photovoltaic technologies. Laser ablation of transparent conductive oxides (TCOs), amorphous silicon structures and back contact removal are standard processes in industry for monolithic device interconnection. However, material ablation with minimum debris and small heat affected zone is one of the main difficulty is to achieve, to reduce costs and to improve device efficiency. In this paper we present recent results in laser ablation of photovoltaic materials using excimer and UV wavelengths of diode-pumped solid-state (DPSS) laser sources. We discuss results concerning UV ablation of different TCO and thin-film silicon (a-Si:H and nc-Si:H), focussing our study on ablation threshold measurements and process-quality assessment using advanced optical microscopy techniques. In that way we show the advantages of using UV wavelengths for minimizing the characteristic material thermal affection of laser irradiation in the ns regime at higher wavelengths. Additionally we include preliminary results of selective ablation of film on film structures irradiating from the film side (direct writing configuration) including the problem of selective ablation of $\mathrm{ZnO}$ films on a-Si:H layers. In that way we demonstrate the potential use of UV wavelengths of fully commercial laser sources as an alternative to standard backscribing process in device fabrication. 


\section{Introduction}

Laser-controlled ablation of individual layers in glass/ transparent conductive oxide (TCO)/thin-film silicon/metal structures is essential for cell isolation and monolithic interconnection in thin-film-silicon photovoltaic technologies. In different fabrication steps of a-Si:H-based devices, material ablation with minimum debris and small heat affected zone with low-processing cost, is one of the main difficulties to achieve for the successful implementation of laser micromachining as competitive technology in this field.

Nowadays DPSS working at IR $(\lambda=1064 \mathrm{~nm})$ and VIS $(\lambda=532 \mathrm{~nm})$ wavelengths are standard tools for thin film module fabrication defining the three steps for monolithic interconnection of these devices (P1: TCO cutting, P2: a-Si structure ablation and P3: back contact removal), but important shunting problems are close related to the inherent thermal affection of laser irradiation at these wavelengths when sources with ns pulse duration are used (Fig. 1).

In previous works, we have demonstrated some of the advantages of using UV wavelengths for minimizing the thermal affection and, therefore, reducing the probability of shunting problems in the device [1,2]. In this work, we have presented the recent results of ablation threshold measurements and process quality assessment using advanced optical microscopy techniques in TCO (Asahi-U, ZnO:Al, ITO) and a-Si samples deposited on glass (including, due to the improved performance in optoelectronic properties associated to the nanocrystalline silicon, some samples of this material). Additionally preliminary results of UV selective ablation of film on film structures are presented, demonstrating the potential use of ns laser sources emitting in the UV as an alternative to standard backscribing process in device fabrication.

For this study we have only used fully commercial laser sources in the ns regime, bearing in mind that thin-film-based photovoltaic technologies are still demanding further reduction in production costs and, nowadays, ultrafast sources are beyond their scope both for the investment and running cost of those equipments. 


\section{Experimental techniques and set-up}

\subsection{Laser sources}

The ablation studies presented in this paper have been carried out using the micromachining laser facilities available at Centro Laser UPM. Laser systems emitting in the UV with ns pulse duration have been used in this work (see Table 1). VIS wavelengths of DPSS lasers were not used due to the fact that this work does not consider backscribing processes and focused only in direct writing from the film side.

Part positioning is assured by $X, Y$ stages which are servo-motor driven stages with linear position encoder (resolution of $0.1 \mu \mathrm{m}$ in each axis). Overall precision in the $X Y$ working area $(100 \mathrm{~mm} \times 100 \mathrm{~mm})$ is about $1 \mu \mathrm{m}$. An additional linear axis ( $Z$ - axis) is used to bring the part to the laser focus.

\subsection{Sample preparation}

Amorphous silicon samples were obtained by hot-wire chemical vapour deposition (HWCVD) in the facilities at the Department of Applied Physics and Optics of Barcelona University. nc-Si samples were obtained by HWCVD under the same conditions that the material used as intrinsic layer in nc-Si:H solar cells [3].

For TCO single layer ablation we used commercial Asahi-U ${ }^{\circledR}\left(\mathrm{SnO}_{2}: \mathrm{F}\right)$ and in-house-prepared ITO ( $\left.\mathrm{SnO}_{2}: \mathrm{In}_{2} \mathrm{O} 3\right)$ deposited by RF magnetron reactive sputtering using a Leybold-Heräus Z400 system. ZnO:Al samples were prepared in a RF sputtering plant using a MV Systems device.

Finally "incomplete" solar cells, using a $\mathrm{ZnO}$ back contact, were made at Universidad de Barcelona to carry out selective-ablation in direct writing configuration as will be discussed later.

\subsection{Measurement and characterization techniques}

Ablation-profile measurements and morphological characterization have 
been made using a confocal laser scanning microscope (CLSM) Leica ICM 1000. The equipment operation wavelength $(635 \mathrm{~nm}$ corresponding to diode laser emission) together with the objective numerical aperture and pinhole diameter gives the final resolution in axial direction. In confocal microscopy techniques, 3D images are obtained by moving the focus plane and acquiring single images (optical slices) that can be put together building up a three dimensional stack of images that can be digitally processed.

The expected accuracy in step measurements is about $20 \mathrm{~nm}$ that corresponds to theoretical calculations according to the objective specifications, however global accuracy in $Z$ measurements is strongly dependent on sample optical reflectivity. Higher reflectivity gives better step measurement accuracy, so the previous value must be considered a reasonable approach taking into account optical behaviour of the studied materials. Additional SEM and EDX images are included for a better comprehension of the morphology of the ablated channels and to obtain qualitative information about selective-ablation process. Most SEM images are presented at same magnification in order to compare at the same scale morphology and dimensions at 248 and $355 \mathrm{~nm}$ irradiation.

Additionally ablation curves and ablation thresholds have been determined. In this method the ablation rate results by comparing the average height in the irradiated zone and the reference level in the untreated material surface. Depending on the irradiation regime different techniques must be applied (see Refs. [4,5] for further details).

All measurements have been performed with environmental temperature and humidity control.

\section{Results}

\subsection{UV ablation of TCO}

Different samples of TCO on glass have been irradiated at 248 and $355 \mathrm{~nm}$ obtaining, as will be discussed later, ablation thresholds in different irradiation conditions. In all cases we produced narrow grooves (widths under $25 \mu \mathrm{m}$ ) with full ablation of the TCO film without substrate damage and with limited thermal affection. The electrical isolation obtained between scribed areas was remarkable 
$\operatorname{good}(>\mathrm{k} \Omega)$.

As an example, using ITO samples we obtained high-quality scribing process at both wavelengths (see. Fig. 2). For irradiation at $248 \mathrm{~nm}$ we used a process velocity of $1 \mathrm{~mm} / \mathrm{s}$, pulse energy of $5 \mathrm{~mJ}$ and a repetition rate of $300 \mathrm{~Hz}$. Process parameters for DPSS irradiation were $0.04 \mathrm{~W}$ mean power, $50 \mathrm{kHz}$ repetition rate and a process velocity of $20 \mathrm{~mm} / \mathrm{s}$.

Ablation thresholds were measured as well for different ITO samples (with the thickness between 0.5 and $1 \mu \mathrm{m}$ ). For $\lambda=248 \mathrm{~nm}$ ablation threshold for all samples is around $0.5 \mathrm{~J} / \mathrm{cm}^{2}$, and for DPSS we found the characteristic strong dependence of the ablation threshold with the laser repetition rate (Fig. 3).

The better morphological quality of the grooves generated at $355 \mathrm{~nm}$ is probably related to the characteristic energy of the photons used $\left(E_{355}=3.49 \mathrm{eV}\right)$, close to the band gap value of the ITO samples $(3.4-3.8 \mathrm{eV})$.

We have assessed the influence of film thickness in the fluence threshold value as well, concluding that this parameter it is not of great relevance for high laser repetition rates (in the range required for obtaining good morphological results in the scribed lines). Fig. 4 shows the results for $\mathrm{ZnO}$ :Al samples of different thicknesses irradiated at different frequencies. An expected slight increase of the ablation threshold with the thickness is clearly shown.

With a fine tuning of the process parameters it is possible to define laser processes of outstanding quality for thin-film TCO processing at $355 \mathrm{~nm}$ with laser sources operating in the ns regime. As an additional example, Fig. 5 shows a CLSM profile of an Asahi-U sample irradiated at $355 \mathrm{~nm}$. The generated groove has a width of only a few microns and the heat-affected zone in the cutting kerf is almost negligible.

\subsection{UV ablation of $\mathrm{a}-\mathrm{Si}$ and $\mathrm{nc}-\mathrm{Si}$}

In order to characterize the UV ablation of thin-film silicon in the temporal regime corresponding to ns laser sources we irradiated samples of a-Si:H and nc-Si (with thicknesses varying between $160 \mathrm{~nm}$ and $1.3 \mu \mathrm{m}$ ). This study has only considered samples of material directly deposited on glass, in order to have 
a deeper understanding of the ablation behaviour of the material.

For a-Si samples irradiated at $248 \mathrm{~nm}$ the ablation thresholds obtained for the samples deposited by PECVD and HWCVD are quite close to those obtained for the TCO samples (ranging from 0.5 to $0.90 \mathrm{~J} / \mathrm{cm}^{2}$ depending on film thickness). However, higher ablation thresholds have been found for nc-Si samples deposited by HWCVD (see Fig. 6). From the morphological point of view the results are poorer if compared with TCO, mainly by the characteristic material spallation observed in the cutting kerfs (Fig. 7).

However, working at $355 \mathrm{~nm}$, the ablation thresholds for a-Si:H are slightly below the ablation thresholds corresponding to Asahi and ITO samples using the same laser repetition rate and quite close to those obtained for $\mathrm{ZnO}: \mathrm{Al}$ samples. We

found ablation thresholds for a-Si:H ranging from $0.08 \mathrm{~J} / \mathrm{cm}^{2}$ (at a frequency of 15 $\mathrm{kHz}$ ) to $0.03 \mathrm{~J} / \mathrm{cm}^{2}$ (at a frequency of $100 \mathrm{kHz}$ ). In Fig. 8 a comparison of ablation thresholds at a fix frequency is presented (including for comparison the values obtained for thin films of characteristic metals).

For DPSS irradiation at $\lambda=355 \mathrm{~nm}$ a characteristic problem of material spraying around the irradiated area is always found (Fig. 9) but, it has been discussed in other works by the authors [4], a fair morphology of the scribed lines can be reproduced in wide process parametric windows.

\subsection{UV selective ablation of film on film structures}

Finally, as an important application of the UV ablation capabilities for photovoltaic material processing, we present preliminary results on film on film selective ablation at $248 \mathrm{~nm}$. We developed specific samples for this study made by depositing a number of "dots" of $\mathrm{ZnO}$ onto an a-Si layer. This two film were itself deposited onto a standard front contact structure (glass + TCO) forming an "incomplete" solar cell. With this configuration (Fig. 10) we were able to determine "in situ" whether the isolation required was achieved, directly measuring the resistivity between dot parts generated by the ablation process (this magnitude could vary three orders of magnitude when complete removal is achieved).

For this study we irradiated the samples with different doses and, additionally, for improving the results, we used process gas as an additional (and 
essential) process variable.

The necessary isolation was achieved with $75 \%$ pulse overlapping, $E \mathrm{p}=$ $5.7 \mathrm{~J} / \mathrm{cm}^{2}$ and 2.5 bar of pure Ar as assist gas. EDX studies was done in order to obtain qualitative information of the groove; Fig. 11 shows SEM and mapping EDX images that highlights the nearly total absence of $\mathrm{Zn}$ and $\mathrm{O}$ on the bottom of the generated groove. This confirms the proper isolation of the groove, giving consistence to the "in situ" resistivity measurements.

\section{Conclusions}

UV lasers sources with pulse widths in the ns regime, are well-suited tools for defining scribing processes in thin-film photovoltaic materials with reduced thermal affection.

We found an outstanding process quality, both from the electrical and morphological point of view, scribing samples of TCO on glass with these sources. Therefore, our study confirms the present trend of using ns UV lasers sources for the first scribing process (P1) in thin film module production.

In addition we have studied the ablation behaviour of a-Si and nc-Si and most of the TCO used in photovoltaic applications when ns UV lasers source are considered. This has been the starting point for the assessment of selective scribing process, irradiating from the film side, for film on film structures. In fact, we present first results of the potential application of this technique in samples specifically designed for evaluating the quality of the scribing laser process generated in the structure.

\section{Acknowledgments}

This work has been made possible by the financial contribution of the Spanish Ministry of Education through research projects CLÁSICO (ENE200767742-C04) and PSE-MICROSIL08. 


\section{References}

[1] C. Molpeceres, S. Lauzurica, J.L. Ocaña, J.J. Gandía, L. Urbina, J. Cárabe, J. Micromech. Microeng. 15 (2005) 1271-1278.

[2] L. Urbina, J.J. Gandía, J. Cárabe, C. Molpeceres, S. Lauzurica, J.L. Ocaña, in: A. Gombert (Ed.), Photonics for Solar Energy Systems; Proceedings of the SPIE, vol. 6189, 2006.

[3] M. Fonrodona, D. Soler, J.M. Asensi, J. Bertomeu, J. Andreu, J. Non-Cryst. Solids 299-302 (1991) 14-19.

[4] P.T. Mannion, et al., Appl. Surf. Sci. 233 (2004) 275-287.

[5] C. Molpeceres, S. Lauzurica, J.L. Ocaña, J.J. Gandia, L. Urbina, J. Carabe, F. Villar, J. Escarré, J. Bertomeu, J. Andreu, in: A. Gombert (Ed.), Photonics for Solar Energy Systems; Proceedings of the SPIE, vol. 6197, 2006. 
Table 1. Characteristics of the laser sources used in this work.

\begin{tabular}{|c|c|c|}
\hline Laser media & Excimer $(\mathrm{KrF})$ & DPSS $3 \omega$ \\
\hline Wavelength & $248 \mathrm{~nm}$ & $355 \mathrm{~nm}$ \\
\hline Pulse duration & $3-7 \mathrm{~ns}$ & $<12 \mathrm{~ns}(50 \mathrm{kHz})$ \\
\hline Beam shape/mode & Rectangular $(3.5 \mathrm{~mm} \times 6 \mathrm{~mm})$ & TEM00 $(\mathrm{M} 2<1.3)$ \\
\hline Frequency & $0-300 \mathrm{~Hz}$ & $15-300 \mathrm{kHz}$ \\
\hline Average power & $0.3-5 \mathrm{~W}(300 \mathrm{~Hz})$ & $5 \mathrm{~W}(50 \mathrm{kHz})$ \\
\hline
\end{tabular}


Fig. 1. SEM image of an a-Si:H sample irradiated at $1064 \mathrm{~nm}$. Thermal affection is clearly visible in the generated groove.

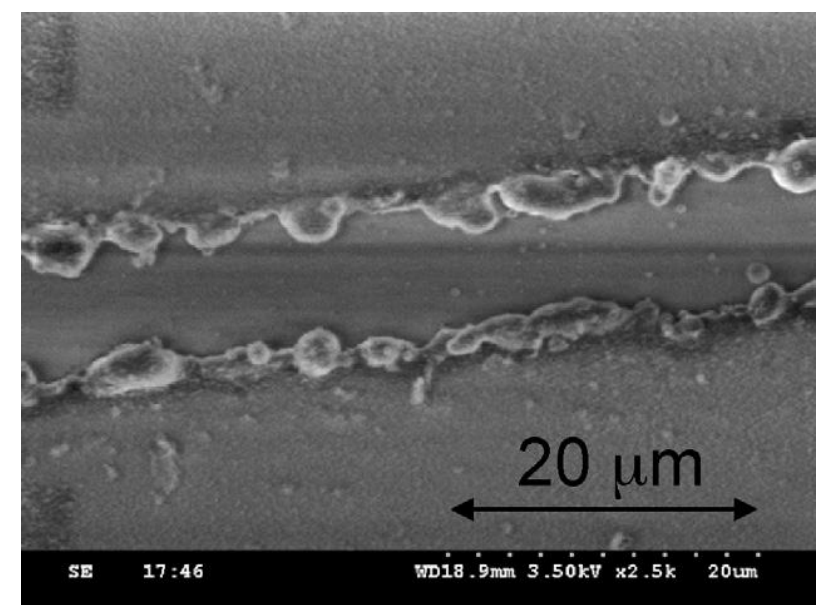


Fig. 2. SEM images and profiles obtained by CLSM of ITO samples ablated with excimer and DPSS lasers.
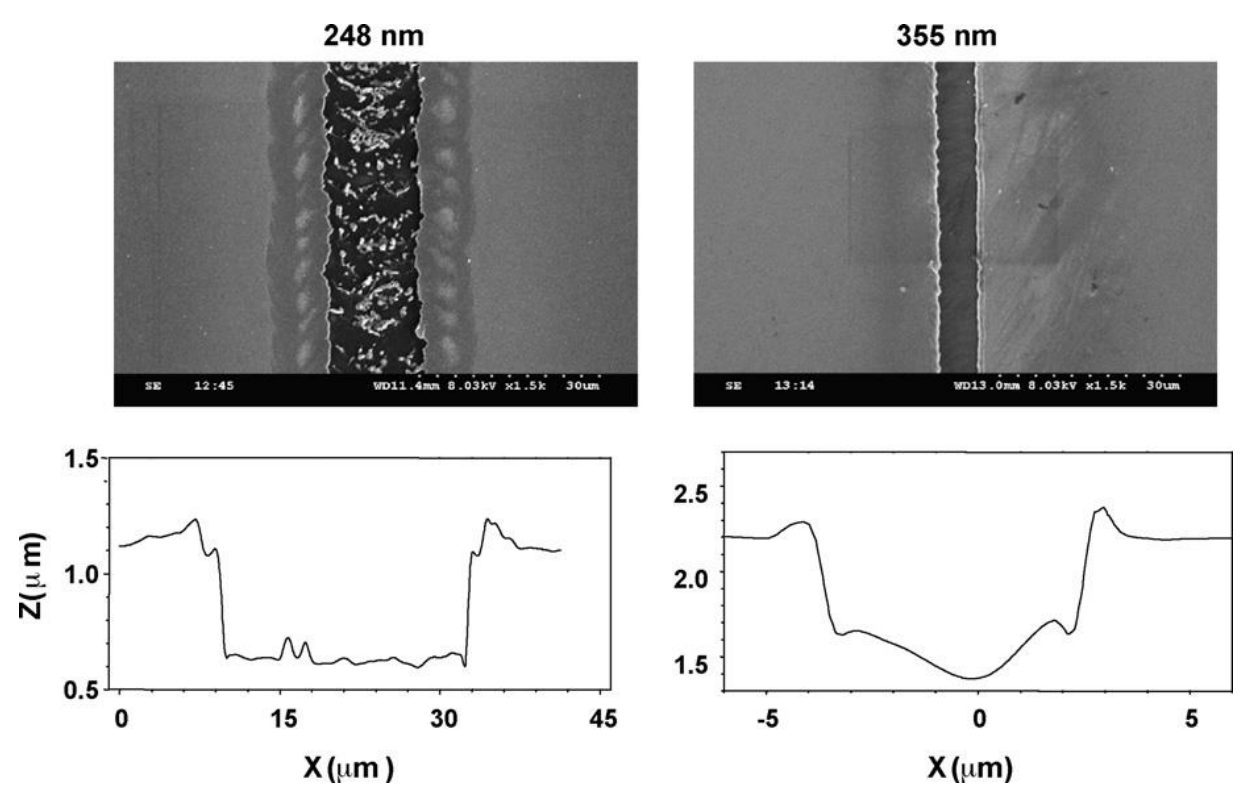
Fig. 3. Ablation thresholds for different frequencies for DPSS irradiation at 355 $\mathrm{nm}$.

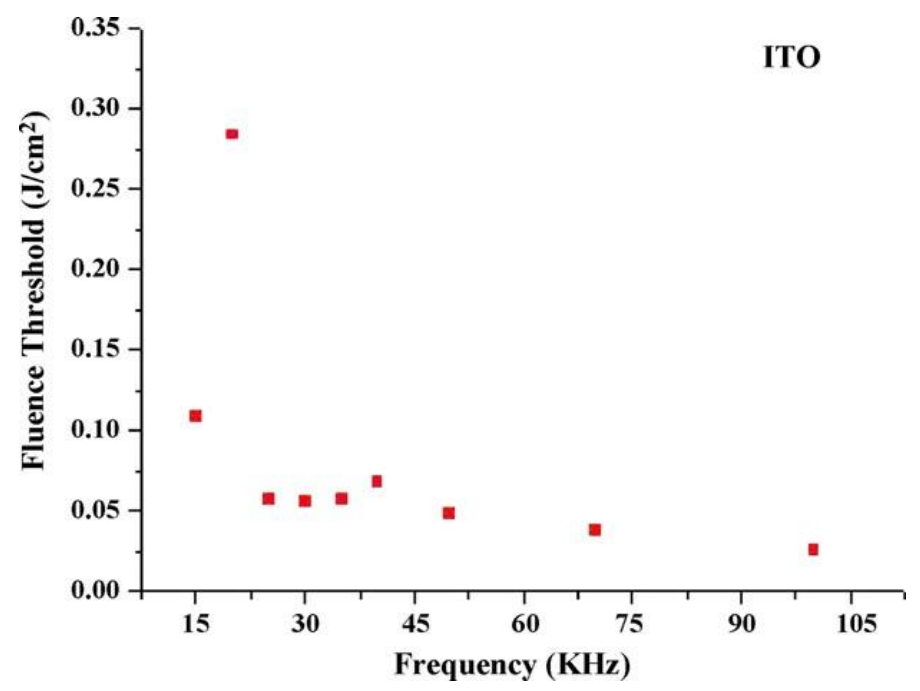


Fig. 4. Influence of film thickness in the ablation threshold value for $\mathrm{ZnO}$ :Al.

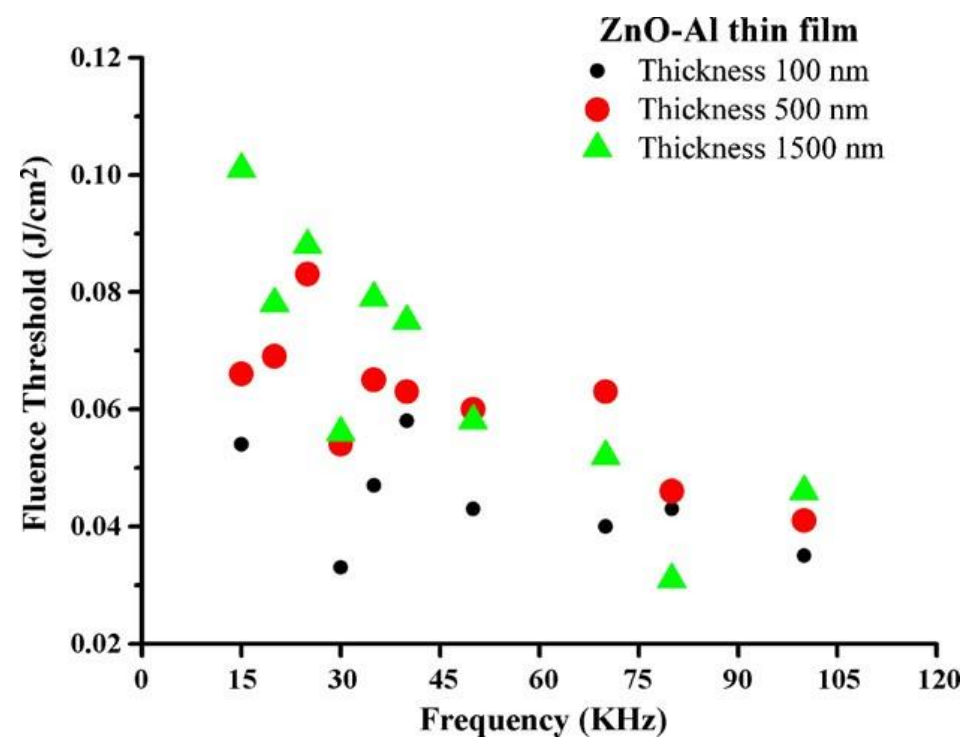


Fig. 5. Ablation profile for a sample of Asahi-U irradiated at $355 \mathrm{~nm}$. The shape of the ablation kerf demonstrates the extremely low thermal affection generated in the process.

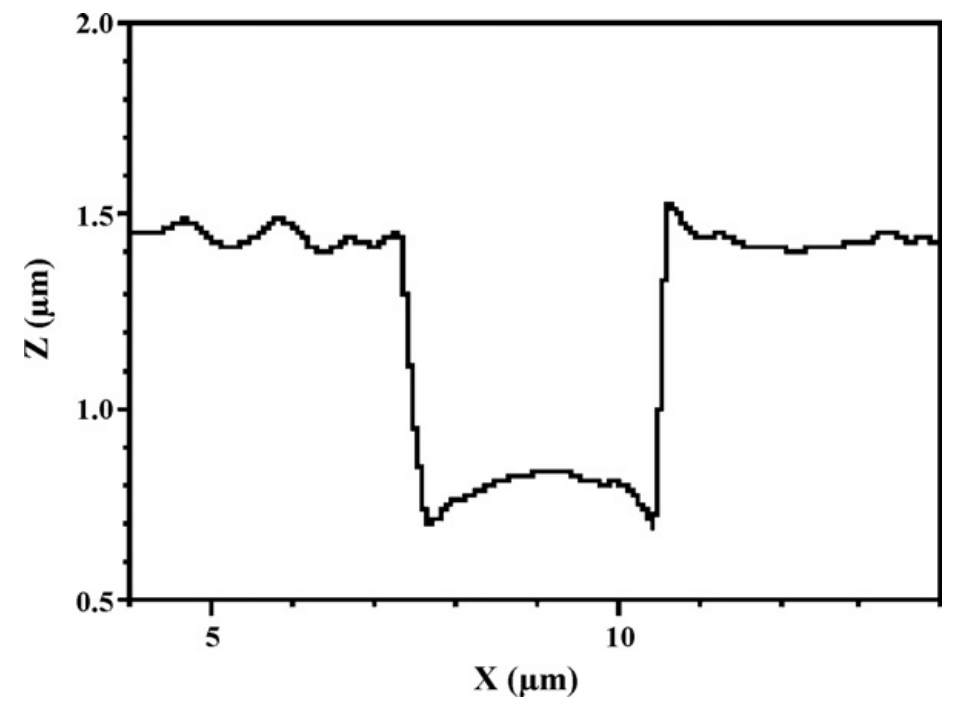


Fig. 6. Ablation curve for obtaining the ablation threshold of an nc-Si sample at $248 \mathrm{~nm}$.

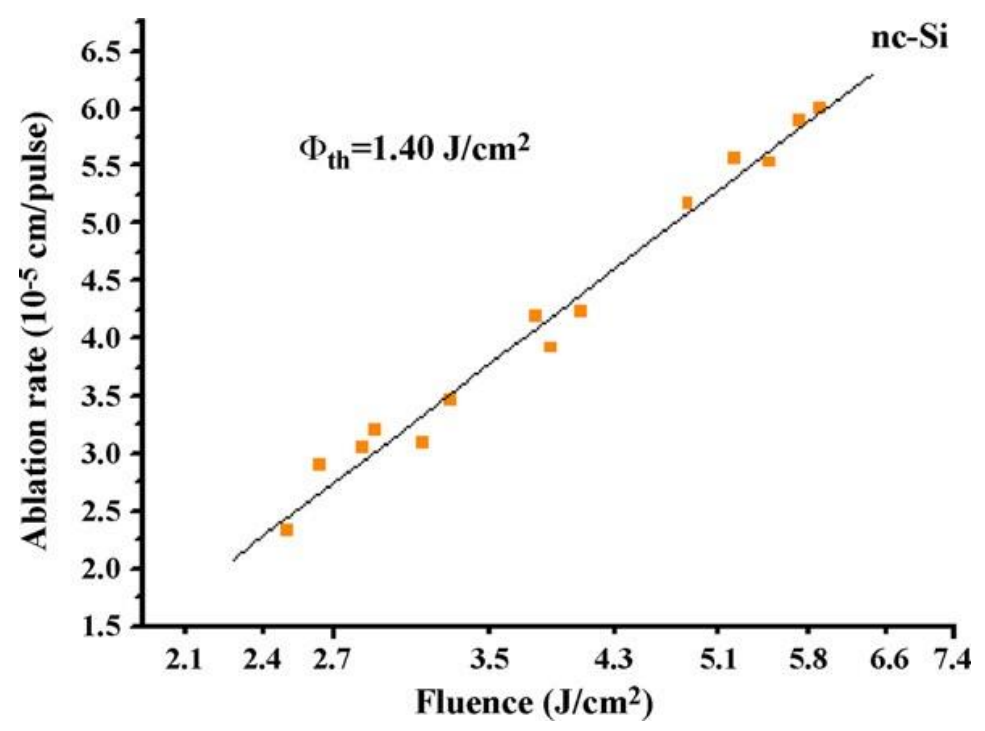


Fig. 7. SEM image of a-Si:H irradiated at $248 \mathrm{~nm}$ (pulse energy was $2.5 \mathrm{~mJ}$, process speed $1.2 \mathrm{~mm} / \mathrm{s}$ and frequency was $300 \mathrm{~Hz}$ ).

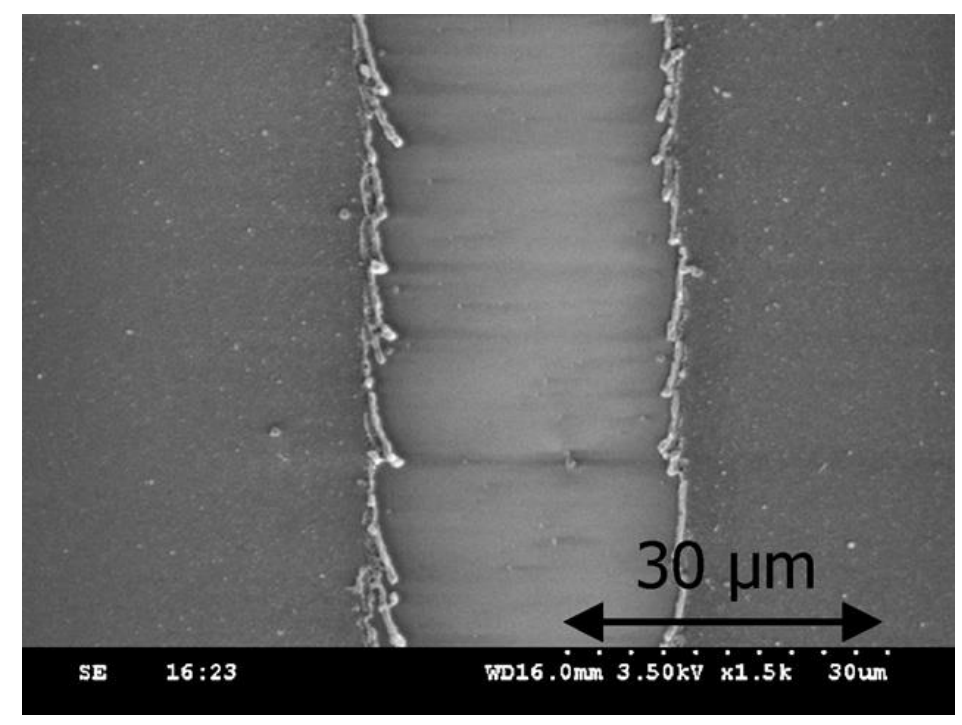


Fig. 8. Ablation thresholds comparison at a given frequency for different materials.

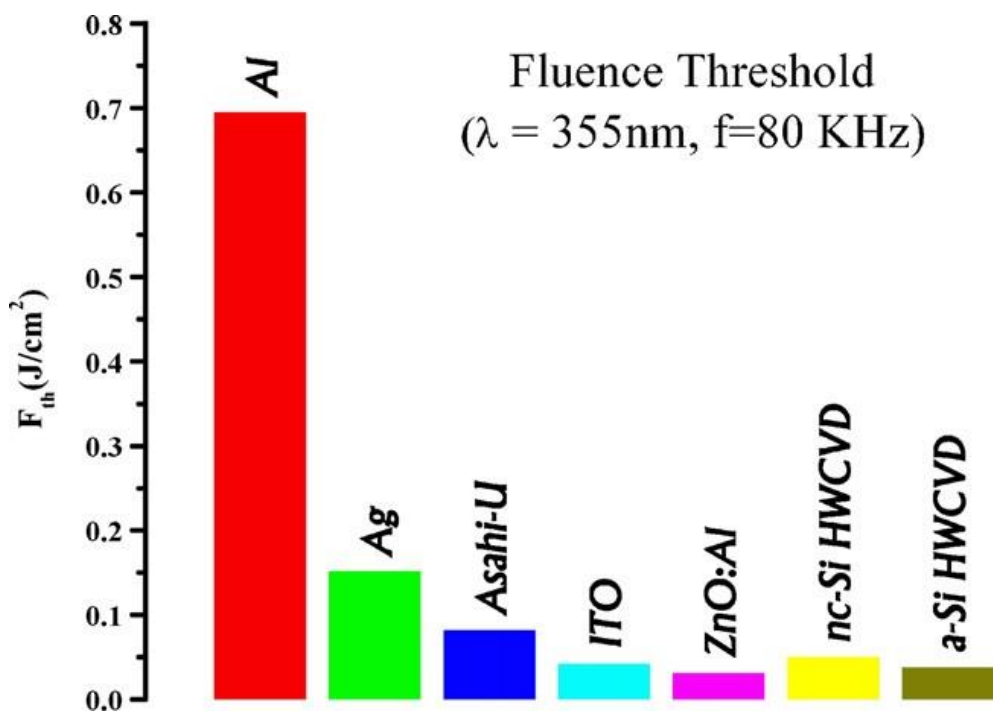


Fig. 9. SEM image of a-Si:H (160 nm thickness) irradiated at $355 \mathrm{~nm}$. Material spraying is clearly visible around the ablated track.

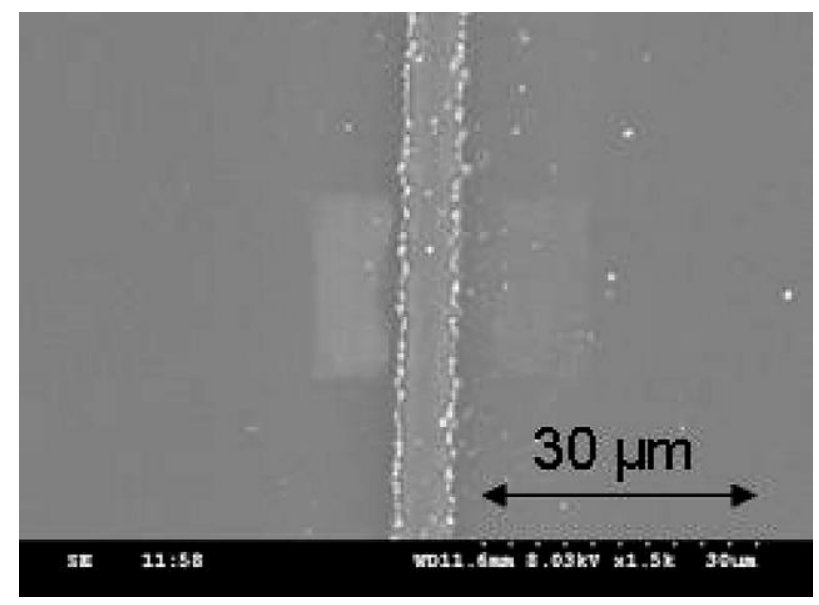


Fig. 10. Structure for selective ablation studies.

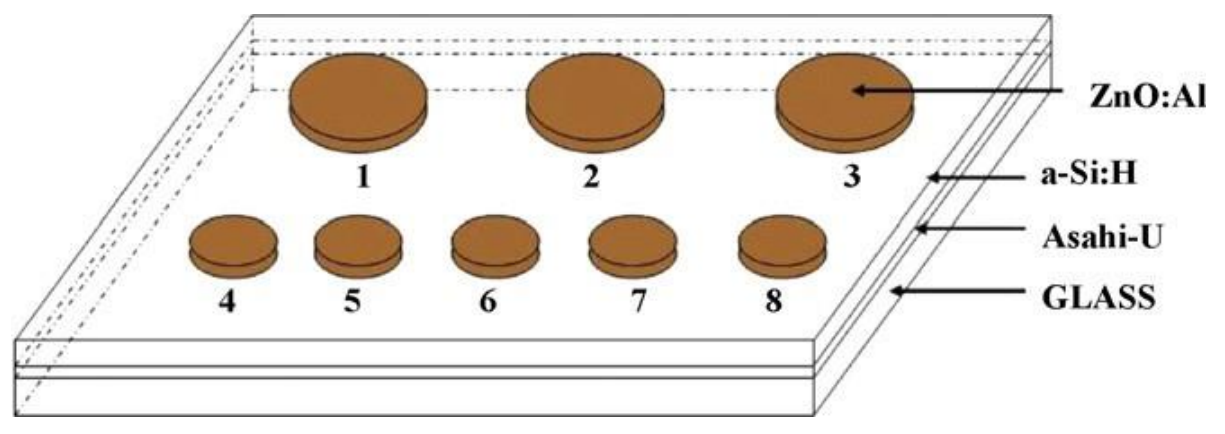


Fig. 11. SEM and EDX analysis of ablated tracks. Absence of $\mathrm{Zn}$ confirms the proper selective ablation of the back contact.

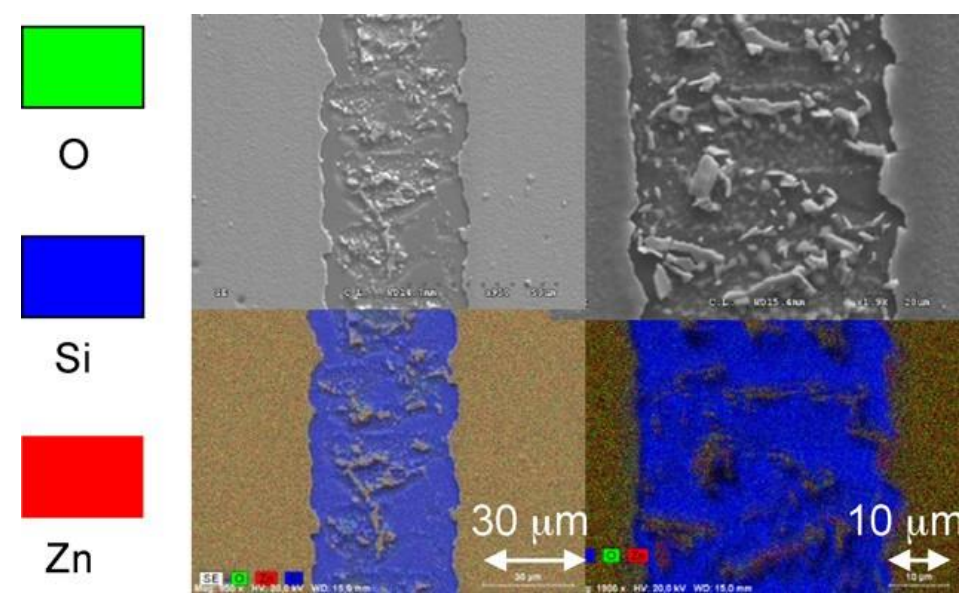

